\title{
Capítulo 11 - A nova face do mundo celeste nas imagens da luneta de Galileu
}

\author{
Paulo Tadeu da Silva \\ Paluana Curvelo Luquiari
}

\section{SciELO Books / SciELO Livros / SciELO Libros}

SILVA, P.T., and LUQUIARI, P.C. A nova face do mundo celeste nas imagens da luneta de Galileu. In: MOURA, B. A., and FORATO, T. C. M., comps. Histórias das ciências, epistemologia, gênero e arte: ensaios para a formação de professores [online]. São Bernardo do Campo, SP: Editora UFABC, 2017, pp. 217-236. ISBN 978-85-68576-84-7. https://doi.org/10.7476/9788568576847.0012.

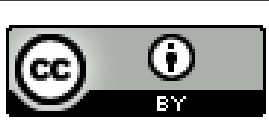

All the contents of this work, except where otherwise noted, is licensed under a Creative Commons Attribution 4.0 International license.

Todo o conteúdo deste trabalho, exceto quando houver ressalva, é publicado sob a licença Creative Commons Atribição 4.0.

Todo el contenido de esta obra, excepto donde se indique lo contrario, está bajo licencia de la licencia $\underline{\text { Creative }}$ Commons Reconocimento 4.0. 


\title{
A NOVA FACE DO MUNDO CELESTE NAS IMAGENS DA LUNETA DE GALILEU ${ }^{1}$
}

\author{
Paulo Tadeu da Silva \\ Paluana Curvelo Luquiari
}

\section{Introdução}

[...] foram necessários ao homem séculos de trabaIho e de coragem intelectual para passar da definição de natureza por naturalmente e de naturalmente por natureza, isto é, da impressão de uma necessidade contra a qual somos impotentes, para a afirmação audaciosa de que a natureza forma um conjunto, de que as próprias coisas se encontram submetidas a uma lei. [...] bastar-nos-á conhecer estas leis para nos situarmos a nós mesmos no nosso lugar neste conjunto, para entrar nele e não nos deixarmos mais dominar por ele - e isso será uma primeira conquista. Depois, dir-se-á um dia: se conhecermos as leis, podemos, pois, servir-nos das coisas e tornar-nos "donos e

\footnotetext{
1 Agradecemos aos membros de nosso grupo de estudos e pesquisa - Caterine, Eduardo, Natan e Victor - pela leitura e pelas sugestões apresentadas, as quais contribuíram significativamente para a clareza do texto e a correção de alguns equívocos.
} 
senhores" da natureza, e isso será uma segunda fase. (LENOBLE, 1969, p. 184-185).

Essa passagem nos coloca diante de um duplo aspecto da filosofia natural desenvolvida ao longo do século XVII. De um lado, é por intermédio dela que se chega à concepção de que os eventos naturais são regidos por leis naturais, cujo conhecimento permite escapar do domínio da natureza sobre o homem; por outro, é precisamente esse conhecimento que fará a inversão entre homem e natureza, isto é, aquilo que permitirá que o homem domine a natureza por meio da ciência e da técnica. Esse duplo aspecto se faz notar em diversos autores do período, dentre os quais Descartes e Galileu são os dois maiores exemplos. Em contraposição a uma concepção teleológica da natureza, em cujo seio coisas e fenômenos também devem ser explicados pelas causas finais, os filósofos modernos priorizaram explicações de cunho mecanicista, nas quais apenas as causas materiais e eficientes serão requisitadas. Um dos motivos para essa mudança de pensamento é que a concepção teleológica da natureza atribuía um animismo aos corpos, bem como sustentava uma visão mágica do mundo; ideia que os autores modernos procuraram contestar (VIDEIRA, 2009, p. 43).

O segundo aspecto, relacionado com o papel da ciência e da técnica no conhecimento do mundo natural, indica uma mudança radical e, em grande medida, relacionada com o modo como os fenômenos naturais serão explicados: a natureza passa a ser encarada de maneira geométrica e matematizada. Esse pensamento é expresso em uma das mais famosas passagens de Galileu, cuja motivação não deve ser desprezada. Se a natureza está expressa em caracteres matemáticos, é porque o conhecimento científico não deve estar subordinado à opinião de quem quer que seja, mas apenas aos cânones que orientam a razão: 
Parece-me também perceber em Sarsi sólida crença que, para filosofar, seja necessário apoiar-se nas opiniões de algum célebre autor, de tal forma que o nosso raciocínio, quando não concordasse com as demonstrações de outro, tivesse que permanecer estéril e infecundo. Talvez considere a filosofia como um livro e fantasia de um homem, como a llíada e Orlando Furioso, livros em que a coisa menos importante é a verdade daquilo que apresentam escrito. Sr. Sarsi, a coisa não é assim. A filosofia encontra-se escrita neste grande livro que continuamente se abre perante nossos olhos (isto é, o universo), que não se pode compreender antes de entender a língua e conhecer os caracteres com os quais está escrito. Ele está escrito em língua matemática, os caracteres são triângulos, circunferências e outras figuras geométricas, sem cujos meios é impossível entender humanamente as palavras; sem ele vagamos perdidos dentro de um obscuro labirinto. (GALILEI, 1973, p. 119).

Desse modo, a fim de compreender a natureza, a ciência deve lançar mão da geometria e da matemática. Sem tais instrumentos, como afirma Galileu, "vagamos perdidos dentro de um escuro labirinto". Se o conhecimento da natureza exige, tal como sustentado por Galileu, o apoio da matemática e da geometria, o desenvolvimento da ciência moderna nos mostra que esse conhecimento também deve ser amparado pela técnica. Com efeito, é por meio dela que os filósofos naturais foram capazes de ampliar a sua capacidade de observação e experimentação, cujo resultado se faz notar tanto na sofisticação das teorias científicas quanto no domínio da natureza pelo homem, aspecto destacado por Lenoble (1969) no trecho anteriormente referido. Assim, a articulação entre a técnica e a matemática estabelece o terreno no qual a ciência moderna colherá seus frutos, com importantes consequências para a observação 
astronômica e a descoberta de uma nova face dos céus. É precisamente nesse último contexto que encontraremos algumas contribuições de Galileu, cujas observações astronômicas têm um impacto relevante no âmbito da cosmologia.

\section{Técnica e ciência: a construção da luneta}

Na Antiguidade e na Idade Média, a elaboração de aparatos técnicos era feita principalmente por artesãos e não por cientistas ou, como chamados na época, filósofos naturais. Quando um deles precisava, por exemplo, de uma lente polida, deveria recorrer a um artesão. No período moderno, essa situação se alterou e os próprios filósofos naturais passaram a desenvolver os instrumentos que necessitavam para o estudo e a investigação dos fenômenos naturais. O desenvolvimento de instrumentos científicos passa a ter uma importância central na filosofia natural do período e, nesse contexto, o nome de Galileu merece, novamente, ser citado.

O filósofo teve notícias de um instrumento que aproximava os objetos, denominado luneta ${ }^{2}$. Tal instrumento, originário da

2 Como apresentado por Leitão (2010, p. 39), no estudo introdutório à tradução portuguesa do Sidereus nuncius, temos, ao menos, três relatos distintos de Galileu sobre como tivera notícias de tal instrumento, a saber: o que informa no Sidereus nuncius, em 1610; o que encontramos em uma carta de 29 de agosto de 1609 a Benedetto Landucci (EN, X, p. 253); e, em 1623, o que está presente em $O$ ensaiador (EN, VI, p. 258). Porém, os historiadores admitem que Galileu tomou o conhecimento da luneta em 1609 por intermédio de seu amigo Paolo Sarpi. Não há consenso sobre quem haveria inventado, de fato, a luneta. Há indícios do uso de tubos ópticos (sem lentes) para o estudo da astronomia desde a Idade Média, e da invenção das primeiras lunetas (tubos ópticos com duas lentes) desde o século XVI, por exemplo: Leonardo da Vinci (por volta de 1508), Thomas Digges e William Bourne (no final do século XVI), Girolamo Fracastoro (invento anunciado em seu livro Homocentrica, de 1538), 
Holanda, tinha uma capacidade de aproximação de cerca de três vezes. Não obstante alguns esforços, Galileu não conseguiu ter em mãos o instrumento holandês e, a partir de algumas descrições, decidiu construir sua própria luneta. Por meio de tentativa e erro - já que não era plenamente versado nas técnicas ópticas -, Galileu conseguiu reproduzi-la cerca de três meses depois que ouviu falar dela.

Ora, mas se a luneta já existia, por que associamos tão fortemente a imagem de Galileu com a do instrumento? Fazemos tal associação porque o filósofo italiano não se contentou apenas em reproduzir a luneta, mas buscou aprimorá-la e conferir-lhe uma finalidade científica. Além disso, o italiano teve a ideia de colocar a luneta em uma base, para oferecer-lhe maior sustentação e realizar observações mais precisas (VIDEIRA, 2009, p. 50). Galileu construiu um instrumento capaz de produzir uma aproximação de cerca de nove vezes, o qual chamou de perspicillum; depois um instrumento que aproximava 20 vezes e chegou à produção de uma luneta que aproximava os objetos em 30 vezes - a qual não utilizou em suas observações astronômicas, por não produzirem imagens muito nítidas, além de limitar o campo de visão, de uma maneira não desejável ao autor (LEITÃO, 2010, p. 44). A despeito do trabalho técnico relacionado com o aprimoramento da luneta, precisamos reconhecer que a maior contribuição de Galileu, isto é, aquela que provocou impactos sem precedentes, diz respeito às suas observações astronômicas.

Antes de analisarmos as observações de Galileu, publicadas pelo autor em um pequeno texto, intitulado Sidereus nuncius (1610), cabe ressaltar que tais observações não foram

Giovanni Baptista Della Porta (em seu livro Magiae naturalis sive de miraculis rerum, de 1558) (LEITÃO, 2010, p. 32-34). 
aceitas de imediato por toda a comunidade científica da época. Isso porque os contemporâneos de Galileu estavam apegados a uma tese filosófica tradicional que questionava o conhecimento obtido através da visão, por considerá-lo incerto e duvidoso. De acordo com essa tese, esse tipo de conhecimento deveria ter alguma comprovação, muitas vezes provinda do tato, para ser tomado como verdadeiro (VIDEIRA, 2009, p. 51-52). Assim, quando Galileu divulgou os resultados de suas observações com seu perspicillum no Sidereus nuncius, a desconfiança quanto à veracidade dos dados visuais obtidos por intermédio desse instrumento foi imediata. Tal desconfiança estava, sem dúvida, relacionada tanto às eventuais ilusões de óptica produzidas pelas lentes quanto, e principalmente, ao fato de que havia um evidente conflito entre as observações de Galileu e as teses cosmológicas admitidas pela tradição filosófica e científica.

Drake (2001, p. 51) sublinha que: "[...] a maioria dos filósofos e astrônomos declararam [as descobertas de Galileu] ilusões de óptica e ridicularizaram Galileu ou o acusaram de fraude". À dificuldade imposta por essa tese filosófica tradicional somaram-se outras, como o fato de ninguém saber explicar perfeitamente o funcionamento da luneta, além do fato de as observações feitas a olho nu apresentarem algumas discrepâncias em comparação com aquelas feitas com o uso do aparato. Diante dessas complicações, Galileu sentiu necessidade de apresentar argumentos teóricos que se somassem às evidências observacionais do Sidereus nuncius. Assim, o autor desenvolveu alguns argumentos físicos que ajudavam a comprovar as observações que havia publicado no Sidereus nuncius, notadamente no que se refere às observações da Lua, bem como argumentos racionais, que visavam a instruir aqueles que fizessem observações com a luneta a interpretá-las corretamente. Tais 
argumentos físicos são encontrados em seu Diálogo sobre os dois máximos sistemas do mundo ptolomaico e copernicano, de 1632 (GALILEI, 2011).

Porém, mesmo diante de todas essas dificuldades, nem todos os contemporâneos de Galileu o acusaram de fraude. Com efeito, uma parte dos filósofos naturais e astrônomos considerava as observações de Galileu não somente verdadeiras, mas fundamentais para que se pudesse colocar em xeque o sistema aristotélico-ptolomaico. Dentre eles, Kepler é um nome que merece destaque. $\mathrm{O}$ astrônomo alemão estava fortemente convencido de que o modelo ptolomaico não representava verdadeiramente o mundo celeste e que, portanto, era preciso constituir um novo sistema astronômico a partir das teses sustentadas por Copérnico em meados do século XVI. Se a habilidade matemática de Kepler permitia-Ihe elaborar, do ponto de vista teórico, um novo sistema astronômico, os dados observacionais de seus contemporâneos - dentre os quais aqueles obtidos por Brahe, foram-lhe os mais caros - representavam o apoio empírico necessário e fundamental para suas conjecturas teóricas.

\section{A nova imagem do céu: as observações astronômicas de Galileu}

A visão hegemônica de mundo no começo do século XVII era aquela proposta pelo sistema aristotélico-ptolomaico. Em resumo, nesse sistema o Cosmo era composto por um conjunto de esferas cristalinas e sólidas que orbitavam a Terra e nas quais os planetas estariam presos. A última esfera era a das estrelas fixas, que limitava esse sistema, do qual a Terra era o centro. 
Havia uma divisão desse Cosmo em duas grandes regiões, a saber, a sublunar e a supralunar. A primeira delas, que se refere à parte do mundo que fica abaixo da Lua, seria composta por quatro elementos, terra, água, ar e fogo. Por ser imperfeita, a região sublunar era caracterizada pela geração e corrupção dos corpos e pela busca de seus respectivos lugares naturais: os corpos graves, constituídos de terra e de água, tenderiam para o centro do Cosmo e os corpos leves, constituídos de ar e de fogo, tenderiam a se afastar do mesmo. A região supralunar, por sua vez, incluía a Lua e tudo o que está acima dela. Tudo nesta região reflete sua perfeição: ela é inteiramente constituída do elemento éter. Não há mudança, geração ou corrupção, pois tudo já se encontra em sua mais perfeita forma, e o único movimento natural existente é o circular, pois apenas esse movimento poderia ser perpétuo e imutável ${ }^{3}$.

Ao dirigir a sua luneta para os céus e observar aquilo que jamais fora visto, Galileu contribui para a derrocada desse cenário tradicional. Portanto, não é surpreendente que o autor comece o Sidereus nuncius afirmando que as coisas que ele propõe são grandiosas, tanto pela excelência do assunto quanto pela sua novidade inaudita e, ainda, pelo instrumento que o auxiliou a tornar essas novidades manifestas (GALILEI, 2010, p. 151). Tais novidades compõem três conjuntos distintos de observações. $\mathrm{O}$ primeiro deles diz respeito à natureza da Lua. Como veremos, as observações de Galileu indicam que a Lua possui um relevo semelhante ao da Terra, além de ser igualmente iluminada por esta última. O segundo conjunto de observações está

3 O movimento circular das esferas celestes é tradicionalmente nomeado como axioma platônico. De acordo com ele, todos os planetas movimentam-se em trajetórias circulares e com velocidade uniforme. Esse axioma dominou toda a tradição cosmológica até Kepler, que o abandona ao estabelecer que os planetas se movem segundo trajetórias elípticas e com velocidade variável. 
relacionado com as nebulosas e a Via Láctea: Galileu conclui que elas são compostas por uma infinidade de estrelas, com enormes distâncias entre si e, portanto, não se poderia mais afirmar a existência de uma esfera das estrelas fixas. Finalmente, o terceiro conjunto de observações refere-se aos satélites de Júpiter, que jamais foram vistos pelos astrônomos.

Galileu não foi o primeiro a fazer observações da Lua com a luneta. Thomas Harriot já fizera e publicara suas conclusões da observação da Lua, bem como um desenho da mesma, quase seis meses antes da publicação do Sidereus nuncius ${ }^{4}$. O italiano, porém, principalmente por conta de sua habilidade artística, foi além do inglês. Como sustenta Panofsky (KOYRÉ, 2011, p. 289), em seu estudo Galileu como crítico das artes: atitude estética e pensamento científico ${ }^{5}$, Galileu era um excelente desenhista, apreciava e compreendia todas as artes subordinadas ao desenho, entre elas, a perspectiva e a relação entre luz e sombra. Quando observou a Lua, além de possuir uma luneta mais potente que aquelas de Harriot, Galileu também foi capaz de produzir um desenho muito mais preciso da superfície da Lua - de fato, se compararmos o desenho do filósofo seiscentista com fotos atuais tiradas por satélites, perceberemos a precisão de seus desenhos. Por ser versado em tais artes, Galileu, ao analisar as manchas mais claras e mais escuras, maiores e menores, presentes na imagem da superfície da Lua vista pela luneta, compara-as com as sombras dos vales e montanhas terrestres e conclui que:

\footnotetext{
4 Harriot - conforme salientam Leitão (2010, p. 56), em nota de rodapé no 65, e Biagioli (2007, p. 78), em nota de rodapé $n$ ㅇ 2 - foi o primeiro a fazer e registrar observações lunares com uma luneta, uma vez que seu primeiro desenho da superfície lunar data de 26 de junho de 1609, quase oito meses antes da publicação do Sidereus nuncius.

${ }^{5}$ Artigo publicado, em março de 1956, em Isis, intitulado Galileo as a critic of the arts: aesthetic attitude and scientific thougth (PANOFSKY, 1956).
} 
[...] a Lua não é de maneira nenhuma revestida de uma superfície lisa e perfeitamente polida, mas sim de uma superfície acidentada e desigual, e que, como a própria face da Terra, está coberta em todas as partes por enormes protuberâncias, depressões profundas, e sinuosidades. (GALILEI, 2010, p. 152).

Portanto, Galileu percebe que a Lua, tal como a Terra, não é perfeita, uma vez que ela possui uma superfície acidentada e desigual. A Lua, diz Galileu, é constituída por cavidades e protuberâncias e é marcada por cadeias de montanhas e profundezas de vales. A implicação de uma afirmação como essa era bastante séria, pois tal fenômeno não seria possível na região supralunar de Aristóteles, uma vez que, para este, a Lua deveria ser lisa e polida. Porém, mais do que apenas afastar a Lua de sua suposta perfeição, Galileu aproximou-a da Terra, retomando a antiga opinião pitagórica ao afirmar que a Lua seria outra Terra, com sua parte mais brilhante representando as superfícies terrosas e sua parte mais obscura, as superfícies aquosas (GALILEI, 2010, p. 159). Seu maior argumento para comprovar tal afirmação é a existência da luz secundária, que indica que também a Terra possui características que acreditávamos existir apenas na Lua: Galileu diz que há, na Lua, uma luz que não viria do Sol, nem de qualquer outra estrela, nem mesmo da própria Lua. Assim, essa luz secundária não poderia ter outra causa que não a Terra. Em suas palavras:

Uma vez, pois, que esta luz secundária não é intrínseca e própria à Lua, e também não é emprestada por nenhuma estrela nem pelo Sol, e visto que na vastidão do mundo não resta nenhum outro corpo a não ser a Terra, pergunto então o que devemos pensar? [...] a Terra, numa troca igual e agradecida, retribui à 
Lua uma luz igual àquela que recebe da Lua durante quase todo o tempo na mais profunda escuridão da noite. (GALILEI, 2010, p. 171).

As observações da Lua por Galileu contribuíram para o questionamento da divisão entre mundo sublunar e supralunar, uma vez que a Lua apresentava, segundo as imagens obtidas pelo telescópio, características semelhantes às da Terra. Outros argumentos, oriundos das demais observações descritas no Sidereus nuncius, somam-se àquilo que é dito sobre a Lua para provar que outros aspectos descritos pelo cosmo aristotélico também estavam equivocados ${ }^{6}$.

Nesse sentido, as observações das nebulosas e da Via Láctea fortalecem a desconfiança de que aquela divisão do mundo em duas regiões não era correta. Como anteriormente citado, o número e a distância entre as estrelas é muito maior do que se acreditava até aquele momento, conforme Galileu apresenta nos seus desenhos das constelações de Órion e das Plêiades. Contudo, de modo análogo aos problemas oriundos da observação da Lua por intermédio da luneta, Galileu justifica inicialmente a maneira como tais astros são vistos a olho nu e com o auxílio daquele instrumento. Ele afirma que a imagem das estrelas e dos planetas não é significativamente aumentada com o uso da luneta, tal como ocorre com objetos mais próximos, inclusive a Lua. Segundo Galileu, a razão de tal fenômeno é a existência de certa "cabeleira de raios brilhantes" tanto nas estrelas fixas como nos planetas, quando observados com a olho nu. Desse modo, sem o auxílio da luneta, não enxergamos esses corpos em seu tamanho simples, mas sempre com a dita

\footnotetext{
${ }^{6}$ Um estudo sobre as consequências dessas observações pode ser encontrado em: Luquiari e Silva (2014).
} 
cabeleira ao seu redor. A presença dessa cabeleira faria com que as estrelas não fossem aumentadas tantas vezes quanto os outros objetos, se compararmos a imagem vista a olho nu com aquela obtida por intermédio da luneta ${ }^{7}$. Além da percepção de que o número de estrelas era muito maior do que se imaginava anteriormente, Galileu afirma que as estrelas que eram chamadas nebulosas são, na verdade, um aglomerado de estrelas muito pequenas ou muito distantes, impossíveis de se diferenciar a olho nu.

O problema do brilho das estrelas ainda foi discutido por Galileu em vários de seus livros até o fim de sua vida, como na terceira Carta sobre as manchas solares (1613), no Discurso dos cometas (1619), em O ensaiador (1623), no Diálogo sobre os dois máximos sistemas do mundo (1632) e em As operações astronômicas, livro que Galileu escreveu no fim de sua vida e deixou incompleto (LEITÃO, 2010, p. 70-71). Porém, a observação com mais implicações e, por esse motivo, a mais contestada, foi a existência de "[...] quatro planetas nunca vistos desde o princípio do mundo até nossos dias" (GALILEI, 2010, p. 179) orbitando Júpiter. De fato, Galileu considerou a observação dessas estrelas como a mais importante observação astronômica relatada no Sidereus nuncius.

A primeira observação de tais estrelas se deu no dia 7 de janeiro de 1610, quando Júpiter se mostrou e Galileu o observou

\footnotetext{
7 A razão disso, segundo Leitão (2010, p. 69), não é a cabeleira cuja existência foi suposta por Galileu, mas sim a difração que ocorre quando a luz passa por uma pequena abertura, como a objetiva da luneta ou a pupila do olho. Tal fato torna impossível que se obtenha imagens nítidas de objetos muito pequenos, como as estrelas, quando vistas à enorme distância que nos encontramos delas. Leitão acrescenta, em nota (número 87), que: “[...] seja qual for o seu tamanho real e a ampliação da luneta, o que se vê são apenas os seus discos de difração" (p. 69).
} 
com a luneta ${ }^{8}$. Ao fazê-lo, o filósofo percebeu que havia três pequenas estrelas perto do planeta. Ainda que ele acreditasse, inicialmente, que elas pudessem ser estrelas fixas, tal fenômeno o intrigou, pois formavam uma linha reta paralela à eclíptica e eram mais brilhantes do que outras estrelas de mesma grandeza. No dia seguinte, quando Galileu tornou a fazer observações do planeta, notou que essas três estrelas se encontravam em um arranjo totalmente diferente do anterior. Por um momento chegou a desconfiar que seu livro de cálculo astronômico estivesse equivocado a respeito do movimento de Júpiter, mas decidiu continuar suas observações diariamente para chegar a uma conclusão a respeito da mudança de posição dessas estrelas. A partir de então, ele passa a observar Júpiter sistematicamente, procedimento minuciosamente descrito em seu livro de 1610.

No dia 9 de janeiro, não conseguiu fazer as observações, pois o céu estava nublado. No dia seguinte, porém, encontrou uma nova configuração: apenas duas estrelas perto de Júpiter, sendo que a terceira havia desaparecido, muito provavelmente porque estava oculta pelo planeta. No dia 11, apesar de as duas estrelas manterem suas posições, a mais oriental parecia maior do que a outra, sendo que no dia anterior elas apresentavam a mesma grandeza. Com essas observações, Galileu concluiu “[...] que existiam no céu três estrelas errantes em torno de Júpiter, como Vênus e Mercúrio em torno do Sol" (GALILEI, 2010, p. 181).

\footnotetext{
8 Leitão (2010, p. 78) menciona - em nota de rodapé no 101 - que, em janeiro de 1610, Júpiter apresentava condições favoráveis para sua observação, pois tinha passado a oposição, quando estava com sua menor distância em relação à Terra. Além disso, Galileu preferia sempre fazer suas observações durante o começo da noite, e, nesta época, apenas Júpiter e Saturno eram visíveis. Uma vez que Saturno estava muito baixo, ou seja, apenas poucos graus afastado do horizonte, Júpiter era o astro mais brilhante da noite, o que favoreceu a observação de Galileu.
} 
No dia 12, a terceira estrela tornou a surgir; mas, no dia 13, pela primeira vez, Galileu avistou quatro pequenas estrelas próximas a Júpiter, formando a mesma linha quase reta - quase, pois a estrela do meio estava um pouco desviada para o norte. As observações dessas estrelas, que só eram interrompidas quando o céu estava nublado, continuaram diariamente até o dia 2 de março de 1610. Durante todo esse período, Galileu tomou nota e desenhou todas as posições das estrelas e de Júpiter, constituindo um longo protocolo de observação.

O autor dedicou sua descoberta a Cosme II, nomeando os satélites que orbitam Júpiter de planetas Mediceus ou de estrelas Mediceias ${ }^{9}$. Apesar de não tratar abertamente do copernicanismo no Sidereus nuncius, a descoberta dessas estrelas foi fundamental para que Galileu se convertesse definitivamente ao novo sistema astronômico, admitindo abertamente sua posição favorável às doutrinas de Copérnico, pela primeira vez, nas Cartas sobre as manchas solares (1613), onde relatou sua observação da existência de manchas no Sol (DRAKE, 2001).

A observação das estrelas Mediceias foi crucial para o copernicanismo, pois comprovava para a comunidade científica da época que era possível que estrelas errantes orbitassem outros planetas, ou seja, que existiam órbitas que não se davam ao redor da Terra. Portanto, ela não poderia ser tomada como o centro dos movimentos de todos os orbes celestes, tal como afirmara Copérnico na primeira descrição de seu sistema heliocêntrico, presente no Commentariolus. Nesse pequeno texto, redigido por volta de 1510, o astrônomo polonês afirma:

9 Galileu fez tal homenagem, pois, percebendo a importância de suas observações, viu que poderia aproveitar-se delas para se aproximar da corte dos Médici. 
"O centro da Terra não é o centro do mundo, mas apenas o da gravidade e do orbe lunar" (COPÉRNICO, 1990, p. 14).

Como afirma Kuhn (2002), a descoberta dos satélites de Júpiter colocava um novo problema a ser investigado e explicado pelos astrônomos do período, a saber: por que determinados corpos celestes orbitavam ao redor de um planeta e não em torno do centro do mundo?

Havia, segundo parecia, novos mundos "nos Planetas" assim como no "Firmamento". Mais importante, estes novos mundos não podiam ser concebidos, nem na hipótese de Ptolomeu nem na de Copérnico, a moverem-se em órbitas quase circulares à volta do centro do universo. Aparentemente, moviam-se à volta de um planeta, e o seu comportamento era, portanto, o mesmo que o da Lua da Terra na astronomia de Copérnico. A velha astronomia, tal como a nova, teria de admitir a existência de satélites, governados pelos planetas. Além disso, e talvez a maior consequência, as observações de Júpiter forneceram um modelo visível do próprio sistema solar de Copérnico. Aqui, no espaço planetário, havia um corpo celeste rodeado pelos seus próprios "planetas", tal como os planetas previamente conhecidos circulavam à volta do Sol. Os argumentos em favor do copernicanismo foram multiplicados pelo telescópio quase tão rapidamente como os próprios corpos celestes. (KUHN, 2002 , p. 237).

O Sidereus nuncius se tornou, portanto, um livro importante para fortalecer os argumentos contra a cosmologia aristotélico-ptolomaica, bem como para defender a cosmologia copernicana, pois as evidências observacionais obtidas por Galileu não poderiam ser explicadas pelo antigo modelo e, por outro lado, fortaleciam as razões em prol do segundo. 
Assim, com o Sidereus nuncius, Galileu inicia o longo combate que realizará, de modo definitivo, a transição entre o antigo modelo cosmológico e o novo, tornando obsoleto o cosmo antigo e medieval compreendido como um todo limitado e hierarquicamente ordenado, constituído por duas regiões heterogêneas compostas de corpos de natureza diferentes e submetidos a leis diferentes. (MARICONDA; VASCONCELOS, 2006, p. 59).

Essas observações também abriram o caminho para que Galileu percebesse, ao defender o copernicanismo, a necessidade de uma física que embasasse esse novo modelo cosmológico, o que propôs no livro que provocou sua condenação pela Igreja, o já citado Diálogo sobre os dois máximos sistemas do mundo ptolomaico e copernicano (GALILEI, 2011).

\section{Considerações finais}

Essa breve exposição sobre as descobertas astronômicas de Galileu nos coloca diante de alguns aspectos centrais da ciência moderna, tendo em vista a íntima relação entre história e filosofia da ciência. O primeiro aspecto diz respeito à elaboração e ao aprimoramento de aparatos técnicos que ampliem a nossa capacidade de observação. Nesse contexto, a invenção e a utilização da luneta é, sem qualquer dúvida, um evento da maior importância. Seja porque ela permitiu a descoberta de novos astros celestes ou a investigação mais precisa daqueles que já eram conhecidos, seja porque sua invenção demandou dos filósofos naturais da modernidade o aprimoramento da técnica de polimento de lentes e a construção de lunetas mais 
poderosas ${ }^{10}$. Desse modo, a utilização desse instrumento científico foi responsável pelas profundas e inevitáveis mudanças no âmbito da astronomia e da cosmologia, determinando o abandono do modelo tradicional e, com ele, a adoção de um novo paradigma.

Esse é o tipo de mudança que uma parte dos historiadores e filósofos da ciência denominam de revolução científica, dentre os quais Kuhn é uma referência obrigatória. Em seu livro A estrutura das revoluções científicas, o autor dedica-se a examinar de que modo as revoluções ocorrem, bem como os diversos fatores que as determinam (KUHN, 1991). Não nos parece fora de lugar afirmar que as observações presentes no Sidereus nuncius são um exemplo de descoberta científica que, por vezes, está na raiz de uma mudança de paradigma. Os fatos descritos por Galileu podem ser tomados como as anomalias que não poderiam ser explicadas pelo modelo proposto por Aristóteles e Ptolomeu e que, portanto, contribuíram decisivamente para a revolução científica levada a cabo por todos aqueles que defenderam as hipóteses aventadas por Copérnico. Se levarmos em consideração o esquema teórico proposto por Kuhn, podemos afirmar que as observações astronômicas de Galileu promoveram a consciência de uma anomalia que mudaria a imagem que se tinha do mundo: abandona-se a visão de um Cosmo limitado em prol da concepção de um Universo infinito. Nesse sentido, o cenário proposto no Sidereus nuncius, ao que tudo indica, adapta-se àquilo que Kuhn (1991, p. 78) afirma na seguinte passagem:

10 Um exemplo disso pode ser encontrado em Descartes, em um dos ensaios que acompanham o Discurso do método (1637), a saber: A dióptrica (AT, 6; BEYSSADE; KAMBOUCHNER, 2009). Os dois últimos discursos desse ensaio são dedicados, respectivamente, à luneta e à maneira de se talhar vidros (técnica diretamente relacionada com a boa construção de lentes). 
A descoberta começa com a consciência da anomalia, isto é, com o reconhecimento de que, de alguma maneira, a natureza violou as expectativas paradigmáticas que governam a ciência normal. Segue-se então uma exploração mais ou menos ampla da área onde ocorreu a anomalia. Esse trabalho somente se encerra quando a teoria do paradigma for ajustada, de tal forma que o anômalo se tenha convertido em esperado.

Contudo, no caso em questão, esse ajuste não foi possível. O declínio da astronomia Ptolomaica foi inevitável, tanto quanto o abandono da cosmologia de inspiração aristotélica. Assim, houve a necessidade de uma mudança do paradigma vigente a fim de explicar as anomalias percebidas por Galileu. Tal necessidade, bem como a primeira impressão dessas anomalias como fraudes inventadas pelo italiano, é constatada no que se segue da passagem supramencionada de Kuhn (1991, p. 78): “[...] até que o cientista tenha aprendido a ver a natureza de um modo diferente o novo fato não será considerado completamente científico". Portanto, em um primeiro momento, as observações de Galileu foram encaradas como aberrações e ilusões, ou seja, de modo não científico. No entanto, as lentes da luneta de Galileu desenharam uma nova face dos céus; assim, definiram uma nova visão de natureza que, consequentemente, carecia de uma nova teoria que a explicasse. Em outras palavras: um novo paradigma científico.

\section{Referências}

ADAM, Charles; TANNERY, Paul (Ed.). CEuvres de Descartes. Paris: Vrin; Centre National du Livre, 2000. 11 v. (AT) 
BEYSSADE, Jean-Marie; KAMBOUCHNER, Denis (Ed.). René Descartes. CEuvres completes - Vol. III: Discours de la Méthode et Essais. Paris: Tel-Gallimard, 2009.

BIAGIOLI, Mario. Galileo's instruments of credit. Chicago: The University of Chicago Press, 2007.

COPÉRNICO, Nicolau. Commentariolus: pequeno comentário de Nicolau Copérnico sobre suas próprias hipóteses acerca dos movimentos celestes. Tradução, introdução e notas de Roberto de Andrade Martins. São Paulo: Nova Stella; Rio de Janeiro: Coppe-MAST, 1990.

DRAKE, Stillman. Galileo: A Very Short Introduction. Oxford: Oxford University Press, 2001.

FAVARO, Antonio (1895). Le opere di Galileo Galilei: edizione nazionale sotto gli auspicii di sua maestà il ré D'italia. Tipografia Di G. Barbéra: Firenze, 1923-1933, v. 20.

GALILEI, Galileu. O ensaiador. 1. ed. São Paulo: Abril Cultural, 1973. (Os Pensadores, vol. XII).

. Sidereus nuncius: o mensageiro das estrelas. Tradução, estudo e notas de Henrique Leitão. 3. ed. Lisboa: Fundação Calouste Gulbenkian, 2010.

- Diálogo sobre os dois máximos sistemas do mundo ptolomaico e copernicano. Tradução, introdução e notas de Pablo Rubén Mariconda. 3. ed. São Paulo: Associação Filosófica Scientiae Studia; Editora 34, 2011.

KOYRÉ, Alexandre. Estudos de história do pensamento científico. Tradução de Márcio Ramalho. 3. ed. Rio de Janeiro: Forense Universitária, 2011. 
KUHN, Thomas S. A estrutura das revoluções científicas. Tradução de Beatriz Vianna Boeira e Nelson Boeira. São Paulo: Editora Perspectiva S. A., 1991.

- A revolução copernicana. Tradução de Marília Costa Fontes. Lisboa: Edições 70, 2002.

LEITÃO, Henrique. Estudo introdutório. In: GALILEI, Galileu. Sidereus nuncius: o mensageiro das estrelas. 3. ed. Lisboa: Fundação Calouste Gulbenkian, 2010. p. 17-136.

LENOBLE, Robert. História da ideia de natureza. Tradução de Teresa Louro Pérez. Lisboa: Edições 70, 1969.

LUQUIARI, Paluana Curvelo; SILVA, Paulo Tadeu da. A dissolução de uma dicotomia aristotélica: alguns argumentos de Galileu em defesa da semelhança entre a Lua e a Terra. Cognitio-Estudos: revista eletrônica de filosofia, v. 11, n. 2, p. 228-38, 2014.

MARICONDA, Pablo Rubén; VASCONCELOS, Júlio. Galileu e a nova física. São Paulo: Odysseus Editora, 2006.

PANOFSKY, Erwin. Galileo as a critic of the arts: aesthetic attitude and scientific thougth. Isis, v. 47, n. 1, p. 3-15, mar. 1956.

VIDEIRA, Antonio Augusto Passos. As descobertas astronômicas de Galileu Galilei. Rio de Janeiro: Vieira \& Lent, 2009. 